\title{
Synapsin I and Synaptophysin Expression during Ontogenesis of the Mouse Peripheral Vestibular System
}

\author{
Eric Scarfone, Danielle Demêmes, and Alain Sans \\ INSERM U 254, Laboratoire de Neurophysiologie Sensorielle, USTL C.P. 089, Place E.Bataillon, F-34095 Montpellier Cedex \\ 5 , France
}

\begin{abstract}
Synapsin I and Synaptophysin are selectively localized in axonal endings of CNS neurons where they are associated with small synaptic vesicle membranes. The development of expression of these 2 proteins was studied by immunocytochemistry during ontogenesis of the peripheral vestibular system in the mouse. Both proteins are localized in vestibular ganglion neurons and in their peripheral sensory extensions as early as gestational day 14. While the entire periphery of these fibers is labeled during embryogenesis, both proteins are subject to relocation during the postnatal maturation of these fibers. In the mature vestibular receptors they disappear from the fibers themselves but are found concentrated in their intraepithelial endings and in the neuronal cell body.

These observations show that the distribution pattern of Synapsin I and Synaptophysin in peripheral extensions of vestibular afferent neurons during development is identical to that described in axonal processes of CNS neurons. This suggests that the peripheral processes of the vestibular afferent neurons present structural and biochemical characteristics of axons. These characteristics are consistent with a bimodal sensory and secretory function of mature endings.
\end{abstract}

Synapsin I and Synaptophysin, 2 proteins associated with the membrane of synaptic vesicles (for a review, see De Camilli and Jahn, 1990), have also been recently localized in sensory endings of the PNS. Synapsin I and Synaptophysin are colocalized in annulospiral sensory endings in the neuromuscular spindle (De Camilli et al., 1988) and in caliceal sensory endings in the vestibular receptors (Scarfone et al., 1988), and Synapsin I has been localized in sensory endings of the taste buds (Finger et al., 1990). In the vestibular caliceal endings, Synapsin I and Synaptophysin localization led to the discovery of a population of vesicles presenting morphological characteristics of synaptic vesicles (Scarfone et al., 1988). These findings suggest the existence of biochemical analogies between the sensory neurites of PNS neurons and axons of CNS neurons.

Received Jul. 23, 1990; revised Nov. 19, 1990; accepted Nov. 21, 1990.

The authors are grateful to Pietro De Camilli for the generous gift of Synapsin I antibodies, for helpful advice and for useful criticism of the manuscript. We are indebted to Reinhard Jahn for kindly providing Synaptophysin antibodies. We also wish to thank J. Boyer and B. Arnaud for skillful editorial and photographic assistance.

Correspondence should be addressed to Eric Scarfone, INSERM U 254, Laboratoire de Neurophysiologie Sensorielle, USTL, C.P. 089, Place E.Bataillon, F-34095 Montpellier Cedex 5, France.

Copyright (C) 1991 Society for Neuroscience $0270-6474 / 91 / 111173-09 \$ 03.00 / 0$
The peripheral extensions of primary afferent neurons convey information to the sensory ganglia where the cell body of the neuron is situated. Moreover, in the case of vestibular receptors and taste buds, they are postsynaptic to sensory cells. In this respect, they can be considered as being functionally similar to dendrites of CNS neurons. However Synapsin I and Synaptophysin are usually not detectable by immunocytochemistry in CNS dendrites, whereas they are highly concentrated in axonal endings where they probably participate in the regulation of the release of neurotransmitter (De Camilli and Jahn, 1990). In axonal endings, Synapsin $I$ is selectively associated with neurotransmitter-containing small synaptic vesicles (SSVs; De Camilli et al., 1983; Navone et al., 1984) and interact with various cytoskeletal elements (Bälher and Greengard, 1987). Synaptophysin is an intrinsic membrane protein of axonal endings' SSVs (Jahn et al., 1985; Navone et al., 1986).

The clear-cut functional difference between axonal and dendritic compartments of CNS neurons is accompanied by biochemical and structural differentiations that develop very early during neurogenesis (Burgoyne and Cambray-Deakin, 1988; Goslin et al., 1988; Goslin and Banker, 1989). One essential occurrence involves the strict segregation of synaptic vesicles and their associated proteins in axonal endings (Cambray-Deakin et al., 1987). The development of Synapsin I and Synaptophysin distribution is closely linked to axonal differentiation (Mason, 1986; Leclerc et al., 1989). To determine whether biochemical analogies between sensory neurites and axons could be extended to ontogenesis of specific proteins, we studied the development of Synapsin I and Synaptophysin immunoreactivity in the peripheral extensions of vestibular afferent neurons.

The development and synaptogenesis of primary afferent fibers of the vestibular system in mammals have been previously studied in our laboratory (Mbiene et al., 1988, 1989; Desmadryl and Sans, 1990). This development is characterized by the massive arrival of afferent fibers at early fetal stages and by the late postnatal maturation of intraepithelial endings. This maturation leads to the formation of large bouton endings and of the characteristic nerve calices. During embryogenesis the presence of small size vesicles has been noted in these afferent fibers (Sans and Dechesne, 1987).

In this article, we demonstrate that analogies between peripheral processes of vestibular afferent neurons and axons of CNS neurons can be extended to the developmental distribution pattern of Synapsin I and Synaptophysin. These results give further support to the hypothesis of a bimodal sensory and secretory function of the adult vestibular afferent endings. 


\section{Materials and Methods}

\section{Animals}

Developing CBA/C57 mice ranging in age from gestational day (GD) 14 to postnatal day (PD) 12, and adults up to 6-months old were used for this study. The presence of a vaginal plug was taken as sign of the beginning of the gestational period (GDI). The day of birth was taken as PDO. For each developmental stage (GD14, GD15, GD16, GD18, PD0, PD2, PD4, PD6, PD8, PD12, 1 month, and 6 months), the 3 animals used came from at least 2 different litters.

\section{Antibodies}

Affinity purificd antibodies directed against Synapsin I (De Camilli et al., 1983) and against the synaptic vesicle protein P38 (Synaptophysin; Jahn et al., 1985) were diluted $0.1-0.05 \mathrm{mg} / \mathrm{ml}$ in $0.1 \mathrm{M}$ phosphate buffer, $\mathrm{pH}$ 7.4. The secondary antibodies used were fluorescein- or rhodaminc-labeled (Biosys), or unlabeled IgG and peroxidase-antiperoxidase (PAP) complexes (DAKO); dilutions were made according to the supplier's instructions.

\section{Tissue preparation}

Two types of preparations were used according to the 2 different immunocytochemical techniques employed (see below). The otocysts of embryos and pups aged up to PD6 were fixed by immersion in a fixative solution containing $4 \%$ formaldehyde and $1 \%$ dimethylsulfoxide in 0.1 $\mathrm{M}$ phosphate buffer, $\mathrm{pH} 7.4 ; 0.2 \%$ glutaraldehyde was added to this solution when the specimens were to be embedded in Epon. Older animals were deeply anesthetized with sodium pentobarbital $(50 \mathrm{mg} /$ $\mathrm{kg}$ ) and transcardially perfused with the same fixative solutions. The vestibular receptors were then dissected out and postfixed in the same fixative solution for $1 \mathrm{hr}$. The specimens were cither impregnated overnight at $4^{\circ} \mathrm{C}$ in $20 \%$ sucrose-phosphate buffer, then subscquently frozen and sectioned at a thickness of $10 \mu \mathrm{m}$ on a cryostat or dehydrated in graded ethanol and embedded in Epon (Epox 812, E.F. Fullam) for cutting $1-\mu \mathrm{m}$-thick semithin sections.

\section{Immunocytochemical staining}

Two complementary immunocytochemical techniques were used in this study. The presence of antigens was always assessed first on frozen sections (pre-embedding techniquc) which gave the best antigen preservation. Precise localization of the antigens (intraepithelial in particular) was then assessed by postembedding techniques on semithin sections. The main advantage of this technique is excellent resolution.

Pre-embedding technique. The frozen sections were reacted overnight at $4^{\circ} \mathrm{C}$ with the primary antibodies. Sections then were incubated at room temperature $(1.5 \mathrm{hr})$ with fluorescein- or tetramethylrhodaminelabeled anti-rabbit IgG, carefully rinsed in antibody-frec dilution medium, mounted in $95 \%$ bidistilled glycerol, and either directly observed or stored at $-30^{\circ} \mathrm{C}$.

Postembedding technique. Semithin plastic sections were deseponized with a solution of $2 \mathrm{gm} \mathrm{KOH}$ added to a mixture of $10 \mathrm{ml}$ methanol and $5 \mathrm{ml}$ propylene oxide (Maxwell, 1978). Immunocytochemical staining was performed using a 5 -step peroxidase-antiperoxidase (PAP) technique adapted from Vacca et al. (1980). The sections were sequentially incubated at room temperature by the following steps: (1) primary antibodies, $1.5 \mathrm{hr}$; (2) unlabeled anti-rabbit $\mathrm{lgG}, 30 \mathrm{~min}$; (3) rabbit PAP complexes, $30 \mathrm{~min}$; (4) unlabeled anti-rabbit IgG, $20 \mathrm{~min}$; and (5) rabbit PAP complexes, 20 min. Between each step the sections were carefully rinsed with PBS $(5 \times 10 \mathrm{~min})$. The bound peroxidase complexes were revealed with $0.05 \%$ 3,3'-diaminobenzidine tetrachloride (Sigma) in the presence of $0.01 \%$ hydrogene peroxide $(5-10 \mathrm{~min}$, room temperature). The sections were then dehydrated and mounted in Entellan (Merck).

\section{Controls}

The antibodies were all affinity-purified and thoroughly characterized (De Camilli et al., 1983; Jahn et al., 1985; Navone et al., 1986). The specificity of the immunocytochemical reactions was assessed by in cubation of 1 section per experiment with nonimmune serum instead of the specific primary antibody. On these sections the immunoreaction was always negative (see Fig. $3 E$ ).

\section{Microscopic analysis}

Observation and microphotography were performed with a Leitz Orthoplan microscope. Incident fluorescent excitation was performed with the Leitz. Pleomopak 2 accessory equipped with a I2/3 filter system for fluorescein isothiocyanate (FITC) and with an N2 filter system for tetramethylrhodamine isothiocyanate (TRITC).

\section{Results}

GD14

Synapsin I and Synaptophysin are present in the immature otocyst, and their distribution is identical (Fig. 1 $A, B$ ). They are localized at the statoacoustic ganglia level. The immunoreactivity is particularly concentrated in bundles of afferent neurites emerging from the ganglia and growing toward the brainstem as wcll as toward the otic vesicle. At the periphery, densely packed immunorcactive fibers are seen under areas where the epithelium limiting the otic vesicle is thicker. These arcas correspond to the future sensory epithelia of the inner ear.

\section{GDI8}

At this stage, the overall morphogenesis of the vestibular part of the otic vesicle is achicved. The primary afferent neurons of the vestibular ganglion and their expanding neurites are immunoreactive for both Synapsin I and Synaptophysin. The afferent fibers can thus be followed on their peripheral path. There bundles of immunoreactive afferent fibers can be found in the sensory receptors. They divide into thick, individualized neurites that penetrate the sensory epithelia. The endings of these fibers form a dense plexus at the base of the future hair cells. A number of slender extensions of these endings can be seen between the sensory cells (Figs. $1 C, 2 A$ ).

\section{Day of birth: PDO}

Synapsin I and Synaptophysin immunoreactivity highlight an increase in the number of afferent neurites in the sensory epithelia (Fig. 2B). Postembedding staining details of this immature innervation can be observed. Fibers penetrate the sensory epithelium at right angles. They join the now extensive plexus of cndings at the base of the hair cells. Higher magnification (Fig. $3, B$ ) shows 2 prominent features: (1) fibers terminating as large patches at the base of cells likely to be future type II hair cells, and (2) elongated, slender neurites originating in the afferent plexus at the base of the hair cells and growing in the middle part of the epithelium. In the latter case, the neurites can be in apposition to hair cells or can aim toward the upper limit of the epithelium without any visible contact with hair cells.

\section{PD2}

Synapsin I and Synaptophysin are again present in Scarpa ganglion neurons and in the fibers that emerge from the ganglion up to their intraepithelial peripheral extremities. Synapsin I immunoreactivity is still evenly distributed along the entire length of the fibers. On the other hand, Synaptophysin immunoreactivity displays a gradient of intensity between the subepithelial part of the less immunoreactive fibers and their more immunoreactive intracpithelial endings (cf. Fig. $4 A, B$ ). The intraepithelial immunoreactive endings undergo reorganization, and the structures present features that are characteristic of calyces (Fig. $4 B$ ).

\section{PD4-PD12}

Intraepithelial immunoreactive endings are at this point always in apposition to hair cells (Figs. $2 C, D ; 3 C^{*}-G$ ). Complete immunoreactive calyces can be observed at PD6 (Fig. 3C); this becomes more prominent at PD12 (Figs. $2 D ; 3 F, G$ ). At PD12, however, some incomplete nerve calyces can still be observed. 

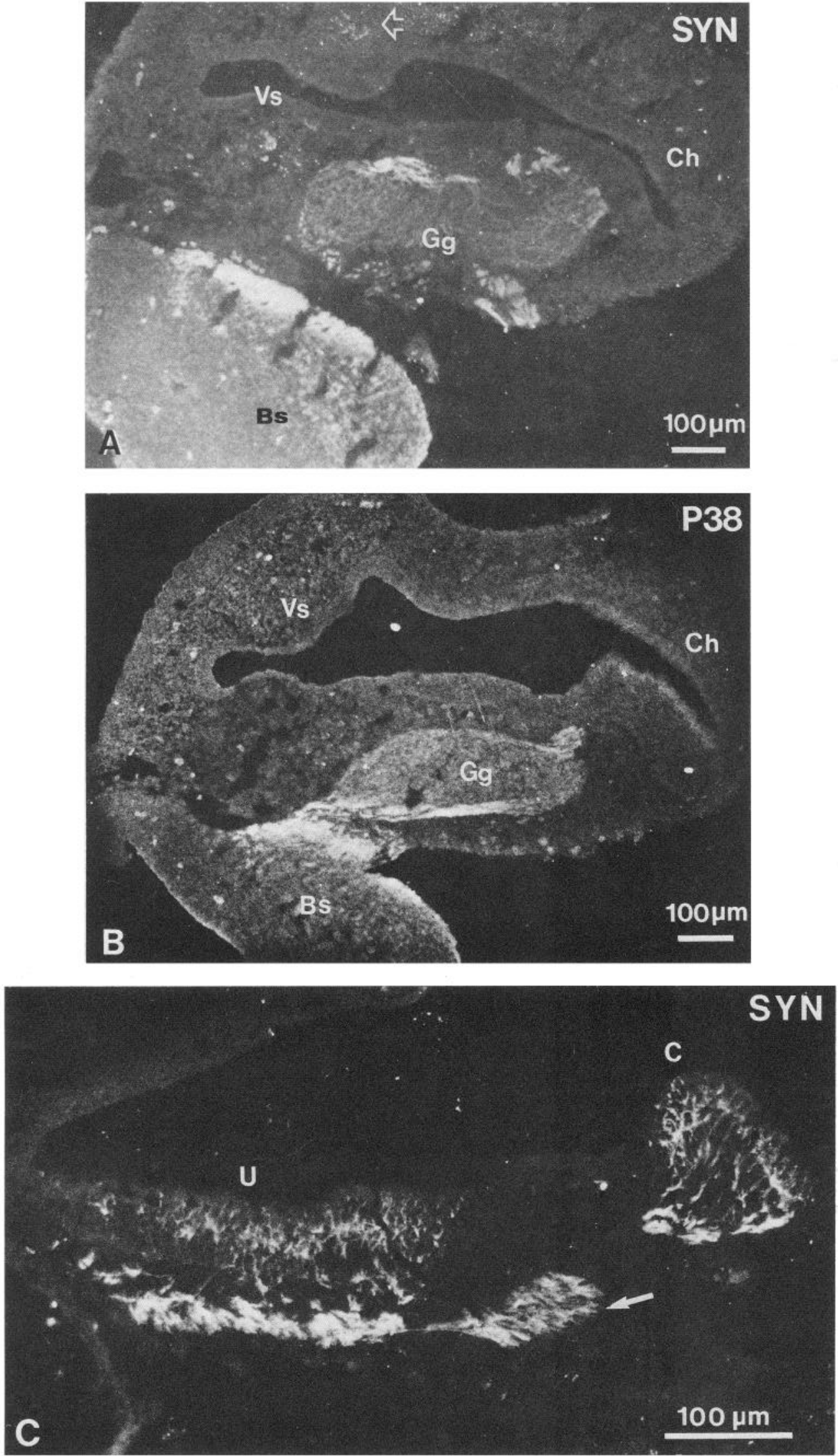

Figure 1. $A$ and $B$, GD14. Comparison of Synapsin I $(S Y N ; A)$ and Synaptophysin $(P 38 ; B)$ immunofluorescence in frozen sections of the same otocyst. Both proteins are present in the statoacoustic ganglion $(G g)$ and in nerve fibers emerging from both its central and peripheral sides. Bundles of immunoreactive fibers are accumulated under the thickened sensory areas of the otic vesicle (arrow in $A$ ). $B$ shows the immunoreactive fibers of the VIIIth nerve emerging from the otic capsule and penetrating the brainstem $(B s)$. The high density of synaptic endings explains the granular aspect of the embryonic brainstem staining. $V s$, vestibular part; $C h$, cochlear part of the otic vesicle. C, GD18. Synapsin I immunoreactivity in a transverse frozen section through an utricle $(U)$ and crista ampullaris $(C)$. Synapsin $I$ is present in nerve bundles forming dense layers under each receptor. Individual afferent fibers emerge from this layer and penetrate both sensory epithelia where they form a network underlining the base of the sensory cells. The upper part of the sensory epithelia contains a large number of slender vertical immunoreactive neurites. The nerve of crista ampullaris in cross section forms a patch of immunoreactive fibers (arrow). 
Synapsin I immunoreactivity is still present in the peripheral part of the fibers but shows a gradient similar to the one previously observed for Synaptophysin. Over this period, Synaptophysin immunoreactivity completely disappears from the subepithelial part of the nerve fibers. It is now segregated in the cell bodies of Scarpa ganglion neurons and in intraepithelial nerve endings.

The subcellular distribution of Synapsin I and Synaptophysin immunoreactivity in the nerve calyces can also be assessed. Both proteins are distributed in the calyces all around the hair cells and tend to aggregate in a punctuate pattern; this tendency is more prominent for Synaptophysin. However, both proteins are clcarly more concentrated in the constricted terminal portion of the nerve calyces that surround the apical part of the type I hair cells. Again this intracaliceal segregation seems to be progressive and takes place earlier for Synaptophysin (Fig. 3, cf. $D-E$ and $F-G$ ). The appearance of synaptic endings of efferent axons, which is known to take place during this period in the mouse, is hardly noticeable because of the density of the immunoreactive afferent innervation.

\section{Adult}

At this phase, Synapsin I and Synaptophysin are both clearly segregated in the neuronal cell bodies of the Scarpa ganglion, and in intraepithelial nerve endings. No immunoreactivity is seen in the fibers themselves between the ganglion and the receptors (Fig. 4C,D).
In the sensory epithelia, both proteins are exclusively localized in the same compartments, namely, the upper extremities of the afferent calyces and the nerve endings at the base of the hair cells (Fig. $4 C_{1}$ ). No immunoreactivity is seen in the preterminal portions of the fibers.

In the cell bodies of Scarpa ganglion neurons, Synapsin I is evenly spread out over the perikaryal cytoplasm. On the other hand, Synaptophysin immunoreactivity is compartmentalized in definite structures scattered throughout the whole cytoplasm; this distribution corresponds to the disposition of the Golgi apparatus in these neurons (cf. Fig. 4, $C_{2}$ and $D_{1}$ ). This difference may be related to the different synthetic pathways of these 2 proteins.

Control. The controls for each stage were unstained as shown in Figure 2E. An unspecific peroxidase reaction is seen only on the otoconia and as a faint coloring of the hair cell bodies.

\section{Discussion}

The present results confirm our previous findings on the presence of Synapsin I and Synaptophysin in afferent endings of adult vestibular sensory receptors (Scarfone et al., 1988). Here we also show that during development, the evolution of Synapsin I and Synaptophysin localization in the peripheral extensions of vestibular primary afferent neurons is identical to that which occurs in axonal compartments of CNS neurons.

In the CNS, after an early developmental stage when all neurites protruding from future neurons are morphologically iden-

\begin{abstract}
Figure 2. $A-D$, Evolution of Synapsin I immunoperoxidase during ontogenesis of vestibular utricle on semithin plastic sections. $A$, GD18; $B$, day of birth (PD0); $C$, PD8; $D$, PD12. Synapsin I is present in the layer of fibers formed by the afferent utricular nerve under the epithelia and in individualized fibers that penetrate the sensory epithelium at right angles. In the epithelium, Synapsin I immunoreactivity demonstrates the growth and maturation of the afferent innervation of the sensory cells. Before birth $(A, B)$, patchy endings contact the hair cells at their base and slender elongated endings grow between the sensory cells. After birth $(C, D)$, the main feature is the growth and maturation of the nerve calices around type I hair cells. At PD8, a number of hemicalices are visible, but complete calices are already numerous. At PD12, most calices are complete, but immature features such as interrupted calices are still visible. Small densely immunoreactive dots, more numerous than at PD8, are probably presynaptic endings of the efferent axons contacting either the base of the nerve calices or the base of the type II hair cells. The otoconial membrane shows an unspecific peroxidase reaction (see $E$ ). $E$, Control section of PD0 utricle incubated with nonimmune serum. Note the absence of specific immunoreactivity and the unspecific accumulation of peroxidase reaction product on the otoconia overlaying the sensory epithelium. A faint coloring allows identification of hair cells.
\end{abstract}

Figure 3. A, PD0. Detail of Synapsin I immunoreactivity on a semithin plastic section of utricle. Large immunoreactive afferent fibers penetrate the immature sensory epithelium and either end up as large boutons at the base of the hair cells (arrows) or continue towards the upper limit of the epithelium as slender neurites apposed to the hair cells or growing freely in the epithelium (arrowhead). The slight stain of the sensory cells is nonspecific (see Fig. 2E). B, PD0; Synaptophysin (P38) immunoreactivity. The features are quite similar to Synapsin I (see $A$ ). $C$, PD6. A completely formed calice displays Synapsin I immunoreactivity along its entire length with a marked accumulation of the protein in its apical part (double arrows). On the right side of the picture an incomplete calice ensheathes a round immature type I hair cell. $D$, PD8; Synapsin I immunoreactivity (detail of Fig. 2C). Three type I hair cells are surrounded by immunoreactive calices. Note the accumulation of the antigen in the apex of the calices (double arrows). Two type II hair cells (stars) are contacted at their base by large immunoreactive, probably afferent, endings. E, PD8; P38 immunoreactivity: section of the utricle presented in $D$ showing 2 immunoreactive calices. $F$, PD12. Synapsin I-immunoreactive calices are cut slightly obliquely and transversally to their length axis and viewed at different heights. The nonimmunoreactive type I hair cell nuclei and cytoplasms are clearly visible encircled by Synapsin I-positive calices. Note the small diameter of calices cut at the apex of the hair cells (double arrows; cf. with double arrows in $D$ or $G$ ). The calices are still strongly reactive along their entire length. $G$, PD12; P38 immunoreactivity. A type I hair cell is surrounded by an immunoreactive calyx. P38 is strongly accumulated in the apical ends of the calyx (double arrow) and barely visible in its laterobasal part.

Figure 4. $A$ and $B$ PD2, Comparison of Synapsin I $(S Y N ; A)$ and $P 38(B)$ immunoreactivity in transverse frozen sections of the same crista. Both proteins are present in the bundled afferent fibers of the crista ampullaris nerve. Synapsin I immunoreactivity is uniform in all preterminal and terminal segments of the fibers while Synaptophysin immunoreactivity is more intense in the intraepithelial endings of these fibers than in their preterminal parts, which are faintly fluorescent. In the sensory epithelium, the afferent endings form a dense plexus at the base of the hair cells. Transversally cut growing nerve calices appear as ring structures at the top of the crista in $B$. $C$ and $D$, Comparison of Synapsin I $(C)$ and $\mathrm{P} 38(D)$ immunofluorescence in a longitudinal frozen section of a vestibular crista, its nerve, and the vestibular ganglion shows that both proteins are not expressed in the nerve fibers (arrows) and arc cnclosed within the intracpithclial cndings (above) and the ccll bodics of affcrent ncurons (below). A folded utricular epithelium $(C)$ is visible in $D$. $C_{l}$ shows that Synapsin I immunoreactivity in the sensory receptor is concentrated in the apical part of the nerve calices and in nerve endings at the base of the cells. $C_{2}$ and $D_{1}$ show immunoreactivity in the vestibular ganglia. Synapsin I ( $\left.C_{2}\right)$ is evenly distributed in the cytoplasm of vestibular afferent neurons while P38 $\left(D_{t}\right)$ is segregated in individualized organelles of these neurons giving a punctiform aspect to the labeling. 

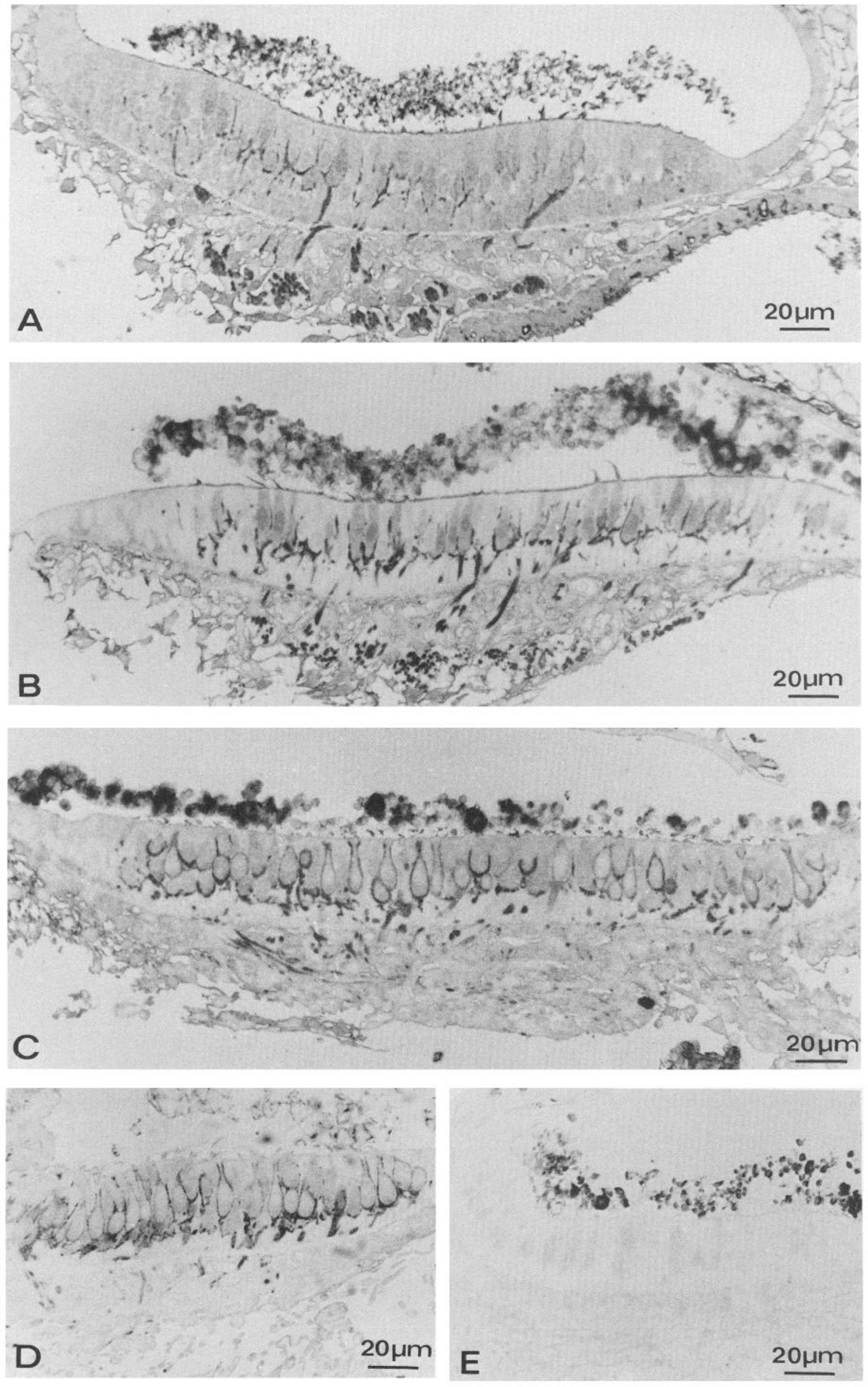

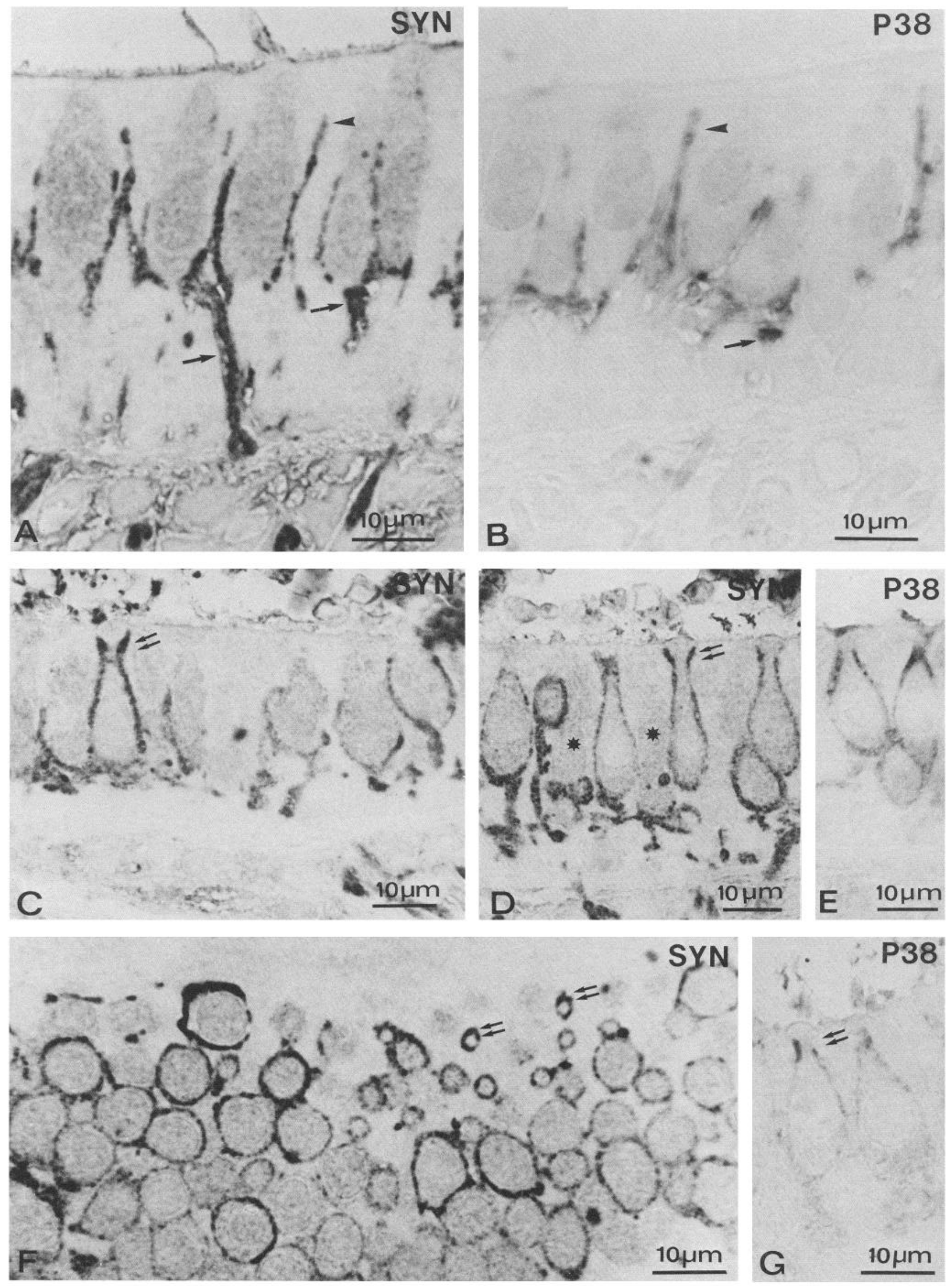

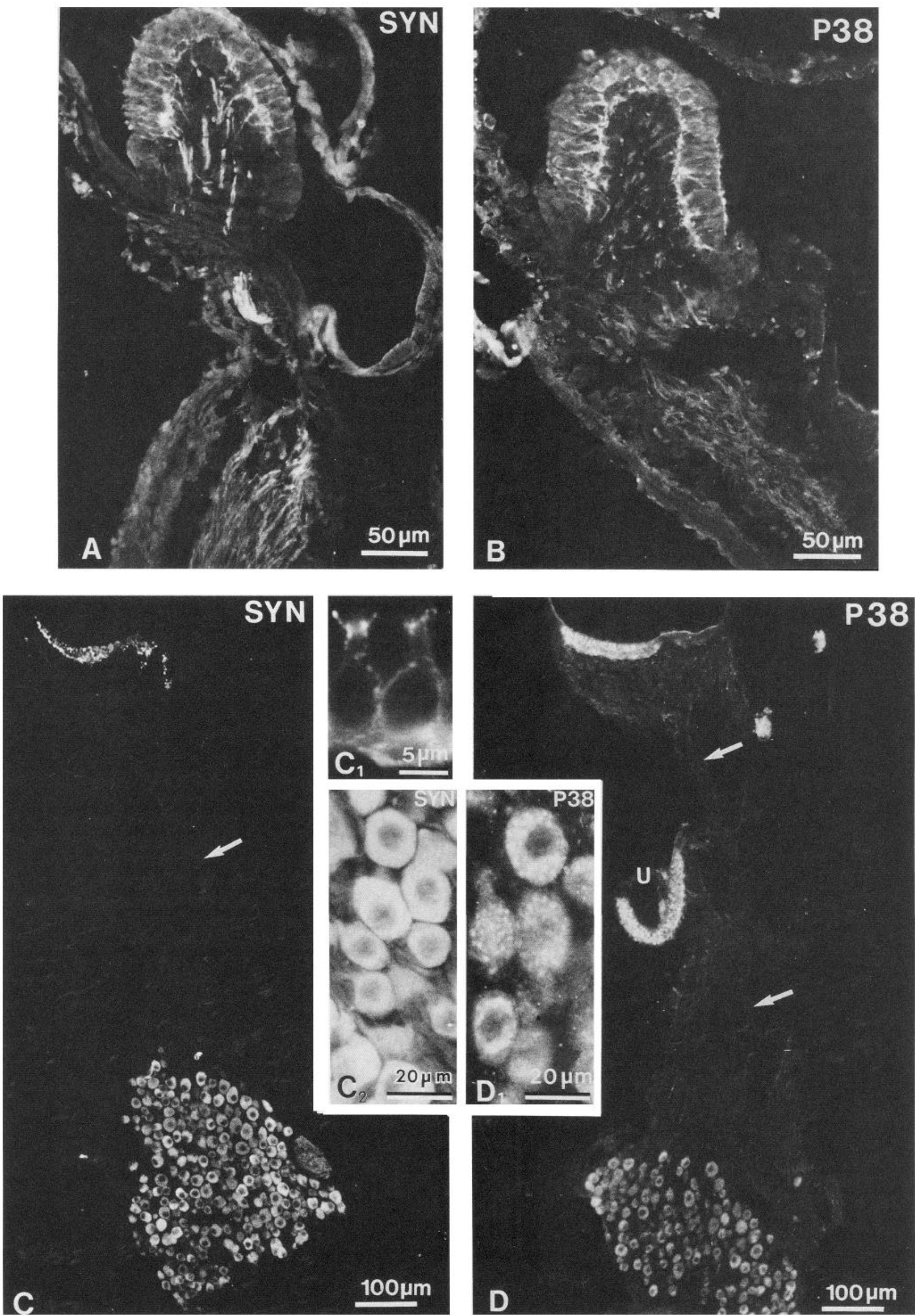
tical, 1 of the processes soon acquires specific axonal features (see Goslin and Banker, 1989). Small-sized vesicles and proteins specific to synaptic endings are among the first constituents to be segregated in the axonal compartments (Sarthy and Bacon, 1985; Cambray-Deakin et al., 1987). This segregation is followed somewhat later by a major reorganization of the cytoskeletal networks of axons and dendrites (Burgoyne and Cambray-Deakin, 1988). This process leads to structurally and biochemically very distinct axonal and dendritic segments. Immunocytochemical detection of Synapsin I and Synaptophysin distribution during development of the CNS shows an evolution that closely matches axonal differentiation. Hence, after a very early stage wherein both proteins are diffusely distributed in the neuron and in all its extensions, they are rapidly no longer detectable in dendrites but remain present along the whole length of the axonal extensions up to the growth cone where they are colocalized with synaptic vesicles (Lohman et al., 1978; Knaus et al., 1986; Mason, 1986; Leclerc et al., 1989). Maturation of the neuron is accompanied by the relocation of both proteins within the axon resulting in a punctuate staining pattern. This pattern indicates an augmentation of their concentration in the axonal synaptic endings and a diminution in the preterminal fibers (Löffler et al., 1986; Mason, 1986; Weiss et al., 1986; Lindsley et al., 1987; Leclerc et al., 1989). These developmental changes are considered to be preparatory steps toward the main function of mature axonal endings, the release of neurotransmitters.

In the mouse vestibular system, both proteins are present, as in the CNS axons, along the entire periphery of the afferent fibers at the earliest embryonic stage studied (GD14). The intense staining of afferent fibers during development enabled us to define features of their growth in the immature vestibular receptors. This demonstrates a potential use of Synapsin I or Synaptophysin immunoreactivity for the study of innervation of the inner ear. Hence, we observed the presence, close to birth, of a transitory increase in the number of slender neurites growing in the hair cell layer of the sensory epithelia. These are reminiscent of the "primitive afferent innervation" observed in human fetuses by electron microscopy (Sans and Dechesne, 1987) and of the transitory "filopods" observed in the mouse by HRP labeling of afferent fibers (Desmadryl and Sans, 1990). In addition, we have been able to visualize the postnatal maturation of intraepithelial afferent endings and, in particular, the growth of caliceal endings around type I hair cells described by electron microscopy in the cat (Favre and Sans, 1979a,b) and in the mouse (Nordemar, 1983). This has only recently been observed at the light microscopy level using HRP labeling (Desmadryl and Sans, 1990).

The presence of Synapsin I and Synaptophysin during early developmental stage could be related to the growth pattern of the peripheral sensory extensions of vestibular primary afferents. These neurites have to grow through connective tissue of the otic capsule. This growth can be reproduced in vitro (Davies, 1989) and is stimulated by displacement of their target tissue (Rose et al., 1977). This behavior is reminiscent of axonal growth and, in the CNS, presence of synaptic vesicles and synaptic vesicle-associated proteins in axonal compartments during development has been tentatively related to the specific growth characteristics of axonal growth cones (Goslin et al., 1988; Kater et al., 1988).

Synapsin I and Synaptophysin continuc to clicit an intense immunoreaction in the endings of the peripheral fibers of the vestibular afferent nerve after contact with the hair cells and during maturation of these endings. During the same period, both proteins gradually disappear from the nerve fibers themselves. This relocation is identical to the redistribution of Synapsin I and Synaptophysin in axons of CNS neurons. We suggest that, as is the case for synaptic endings of CNS axons, the changes we observe here indicate a secretory function of the mature afferent endings (see Scarfone et al., 1988).

This progressive segregation ends in the same immunoreactive pattern for both proteins. It occurs, however, more rapidly for Synaptophysin (achieved at PD12) than for Synapsin I (achieved at adult stage). In the mature synaptic endings, both proteins are associated with SSVs (Navonc ct al., 1984, 1986), but the region of the neuron where association of Synapsin I with the membrane of synaptic vesicles takes place is not known (De Camilli and Navone, 1987). Synapsin I is also associated with cytoskeletal elements (Bähler and Greengard, 1987). This raises the possibility that during development, Synapsin I migrates with the cytoskeletal pool and becomes associated with vesicles only in the synaptic terminal. These changes in immunoreactivity pattern might also result from affinity changes. Multiple Synapsin I RNA types are expressed during differentiation and development, some being specific to undifferentiated forms (Romano et al., 1987) and to immature forms (Haas and De Gennaro, 1988). Affinity differences between immature and mature forms could explain the fiber staining and the transient discrepancy between the 2 synaptic vesicle-associated proteins that we have observed.

Synapsin I and Synaptophysin also elicit a bright immunocytochemical reaction in the cell bodies of vestibular afferent neurons. The pattern of this reaction is different for each protein. It reflects their site of synthesis. The cytoplasmic protein Synapsin I is synthesized on free ribosomes in the cytoplasm, while the membrane protein Synaptophysin transits by the Golgi apparatus (De Gennaro et al., 1983; Navone et al., 1986).

In conclusion, the development of Synapsin I and Synaptophysin distribution and their stabilization in the peripheral endings of vestibular primary afferent neurons is consistent with an axonal nature of these neurites. Owing to their primary function, which is to receive sensory information from the sensory cells, the "dendrite" label is sometimes used for the peripheral arborization of these neurites. We suggest that this denomination is misleading with respect to their biochemical characteristics and that their ability to release neurotransmitters or neuromodulators like axonal presynaptic endings should be considered.

\section{References}

Bähler M, Greengard P (1987) Synapsin I bundles F-actin in a phosphorylation-dependent manner. Nature 326:704-707.

Burgoyne RD, Cambray-Deakin MA (1988) The cellular neurobiology of neuronal development: the cerebellar granule cell. Brain Res Rev 13:77-101.

Cambray-Deakin MA, Norman K-M, Burgoyne RD (1987) Differentiation of the cerebellar granule cell: expression of a synaptic vesicle protein and the microtubule-associated protein MAP1A. Dev Brain Res 34:1-7.

Davies AM (1989) Intrinsic differences in the growth rate of early nerve fibers related to target distance. Nature 337:553-555.

De Camilli P, Jahn R (1990) Pathways to regulated exocytosis in neurons. Annu Rev Physiol 52:625-645.

De Camilli P, Navone F (1987) Regulated secretory pathways of neurons and their relation to the regulated secretory pathway of endocrine cells. Ann NY Acad Sci 493:461-479.

De Camilli P, Cameron R, Greengard P (1983) Synapsin I (Protein 
I), a nerve terminal-specific phosphoprotein. I. Its general distribution in synapses of the central and peripheral nervous system demonstrated by immunofluorescence in frozen and plastic section. J Cell Biol 96:1337-1354.

De Camilli P, Vitadello M, Canevini MP, Zanoni R, Jahn R, Gorio A (1988) The synaptic vesicle proteins synapsin I and synaptophysin (protein 38) are concentrated both in efferent and afferent nerve endings of the skeletal muscle. J Neurosci 8:1625-1631.

De Gennaro LJ, Kanazir S, Wallace WC, Lewis RM, Greengard P (1983) Neuron-specific phosphoproteins as models for neuronal gene expression. Cold Spring Harbor Symp Quant Biol 48:337-345.

Desmadryl G, Sans A (1990) Afferent innervation patterns in crista ampullaris of the mouse during ontogenesis. Dev Brain Res 52:183189.

Favre D, Sans A (1979a) Morphological changes in afferent vestibular hair cell synapses during the postnatal development of the cat. $\mathbf{J}$ Neurocytol 8:765-775.

Favre D, Sans A (1979b) Embryonic and postnatal development of afferent innervation in cat vestibular receptors. Acta Otolaryngol 87: 97-107.

Finger TE, Womble M, Kinnamon JC, Ueda T (1990) Synapsin I-like immunoreactivity in nerve fibers associated with lingual taste buds of the rat. J Comp Neurol 292:283-290.

Goslin K, Banker $G$ (1989) Experimental observations on the development of polarity by hippocampal neurons in culture. J Cell Biol 108:1507-1516.

Goslin K, Schreyer DJ, Pate Skene JH, Banker G (1988) Development of neuronal polarity: GAP-43 distinguishes axonal from dendritic growth cones. Nature 336:672-674.

Haas CA, De Gennaro LJ (1988) Multiple synapsin I messenger RNAs are differentially regulated during neuronal development. J Cell Biol 106:195-203.

Jahn R, Schiebler W, Ouimet C, Greengard P (1985) A 38,000-dalton membrane protein (p38) present in synaptic vesicles. Proc Natl Acad Sci USA 82:4137-4141.

Kater SB, Mattson MP, Cohan C, and Connor T (1988) Calcium regulation of the neuronal growth cone. Trends Neurosci 11:315-321.

Knaus P, Betz H, Rehm H (1986) Expression of synaptophysin during postnatal development of the mouse brain. J Neurochem 47:13021304.

Leclerc N, Beesley PW, Brown I, Colonnier M, Gurd JW, Paladino T, Hawkes R (1989) Synaptophysin expression during synaptogenesis in the rat cerebellar cortex. J Comp Neurol 280:197-212.

Lindsley TA, De Camilli P, Banker GA (1987) The influence of cellcell contact on the distribution of synapsin I in hippocampal neurons in culture. Soc Neurosci Abstr 13:88.7, p. 318.

Lohmann SM, Ueda T, Greengard P (1978) Ontogeny of synaptic phosphoproteins in brain. Proc Natl Acad Sci USA 75:4037-4041.

Löffler F, Lohmann SM, Walckhoff B, Walter U, Hamprecht B (1986)
Immunocytochemical characterization of neuron-rich primary cultures of embryonic rat brain cells by established neuronal and glial markers and by monospecific antisera against cyclic nucleotide-dependent protein kinases and the synaptic vesicle protein synapsin $I$. Brain Res 363:205-221.

Mason CA (1986) Axon development in mouse cerebellum: embryonic axon forms and expression of synapsin I. Neuroscience 19:13191333.

Maxwell MH (1978) Two rapid and simple methods used for the removal of resins from $1.0 \mu \mathrm{m}$ thick epoxy sections. J Microsc 112: 253-255.

Mbiene JP, Favre D, Sans A (1988) Early innervation and differentiation of hair cells in the vestibular epithelia of mouse embryos: SEM and TEM study. Anat Embryol 177:331-340.

Mhiene JP, Dechesne CJ, Schachner M, Sans A (1989) Immunocytochemical characterisation of the expression of cell adhesion molecule Ll during early innervation of mouse otocysts. Cell Tissue Res 255:81-88.

Navone F, Greengard P, De Camilli P (1984) Synapsin I in nerve terminals: selective association with small synaptic vesicles. Science 226:1209-1211.

Navone F, Jahn R, Di Gioia G, Stukenbrok H, Greengard P, De Camilli $P$ (1986) Protein p38: an integral membrane protein specific for small vesicles of neurons and neuroendocrine cells. J Cell Biol 103: 2511-2527.

Nordemar H (1983) Postnatal development of the vestibular sensory epithelium in the mouse. Acta Otolaryngol 96:447-456.

Romano C, Nichols RA, Greengard P, Greene LA (1987) Synapsin I in PC12 cells. I. Characterization of the phosphoprotein and effect of chronic NGF treatment. J Neurosci 7:1294-1299.

Rose JE, Sobkowicz HM, Bereman B (1977) Growth in culture of peripheral axons of the spiral ncurons in responsc to displacement of the receptors. J Neurocytol 6:49-70.

Sans A, Dechesne CJ (1987) Afferent nerve ending development and synaptogenesis in the vestibular epithelium of human fetuses. Hearing Res 28:65-72.

Sarthy PV, Bacon W (1985) Developmental expression of a synaptic vesicle-specific protein in the rat retina. Dev Biol 112:284-291.

Scarfone E, Demêmes D, Jahn R, De Camilli P, Sans A (1988) Secretory function of the vestibular nerve calyx suggested by presence of vesicles, synapsin I and synaptophysin. J Neurosci 8:4640-4645.

Vacca LL, Abrahams SJ, Naftchi NE (1980) A modified peroxidaseantiperoxidase procedure for improved localization of tissue antigens: localization of substance $\mathrm{P}$ in rat spinal cord. J Histochem Cytochem 28:297-307.

Weiss S, Pin JP, Sebben M, Kemp DE, Sladcczek F, Gabrion J, Bockaert J (1986) Synaptogenesis of cultured striatal neurons in serum-free medium: a morphological and biochemical study. Proc Natl Acad Sci USA $83: 2238-2242$. 